\title{
Decolonización, bibliotecas y América Latina: notas para la reflexión
}

\author{
Daniel Guillermo Gordillo Sánchez*
}

Artículo recibido:

2 de febrero de 2015

Artículo aceptado:

15 de abril de 2016

\section{Resumen}

El objeto del presente artículo es reformular el papel de la biblioteca en América Latina considerando las particularidades históricas y culturales de la región. A partir de una aproximación filosófica y antropológica, se plantea la perspectiva de la decolonización del conocimiento como un mecanismo para transformar el modelo epistémico existente, el cual privilegia los conocimientos occidentales sobre los no-occidentales. Se discuten las implicaciones que tiene la noción de razón instaurada por la Europa moderna, la cual terminó de desvalorizar los conocimientos o saberes tradicionales, marginalizados desde tiempos de la Colonia. Por tanto, también se hace necesaria una reflexión crítica

* Universidade Federal de Santa Catarina. Programa de Pós-Graduação en Antropologia Social (PPGAS), Brasil. danielgordillo65@gmail.com 
sobre el discurso de la gestión del conocimiento. Se defiende a la biblioteca como una institución social y democrática, donde converja una ecología de saberes, en la cual puedan coexistir diversas formas de producción de conocimiento y, al mismo tiempo, que permita recuperar los valores y las manifestaciones culturales de los pueblos originarios. Finalmente se amplía la visión de la Biblioteca Multicultural, formalmente reconocida por la IFLA y la Unesco en el año 2008, institución pensada para integrar cosmovisiones y prácticas de poblaciones con características culturales diversas.

Palabras clave: Bibliotecas Multiculturales; Decolonización; Interculturalidad; Pluralismo Epistemológico; América Latina.

\section{Decolonization, libraries and Latin America: notes for reflection \\ Daniel Guillermo Gordillo-Sánchez}

\section{Abstract}

The object of the present paper is to reformulate the library in Latin America on the basis of the historical and cultural conditions of the region. From a philosophical and anthropological approach, this study proposes the decolonization of knowledge as a mechanism for transforming the existing epistemological model that privileges the Western knowledge while disadvantaging other non-Western epistemologies. The paper analyzes the implications of the European notion of reason, arguing that since colonial times this perspective has devaluated and marginalized traditional knowledge. The study also reflects on the discourse of knowledge management, asserting that the library is a social and democratic institution, where diverse forms of knowledge can coexist. As such, the library should promote the recovery of cultural values and manifestations of indigenous peoples. Finally, the study expands the vision of the Multicultural Library, formally recognized by IFLA and UNESCO in 2008, as an institution designed to integrate worldviews and practices of populations of diverse cultural features.

Keywords: Multicultural Libraries; Decolonization; Interculturality; Epistemological Pluralism; Latin America. 


\section{INTRODUCCIÓN}

A ntes del fin, uno de los últimos legados de Ernesto Sabato, termina de desnudar el pensamiento del argentino, y se destaca, antes que nada, por ser una biografía moral, una especie de testamento donde se cuestionan, entre otros fenómenos de la sociedad moderna, la robotización del hombre y la idolatría a la técnica, revelando la preocupación que este autor tenía frente al legado racionalista heredado de Europa y sobre todo, frente a la crisis generalizada que actualmente vive el mundo: "Allí expuse mi desconfianza y mi preocupación por el mundo tecnólatra y cientifisista, por esa concepción del ser humano y de la existencia que empezó a sobrevalorarse cuando el semidiós renacentista se lanzó con euforia hacia la conquista del universo, cuando la angustia metafísica y religiosa fue reemplazada por la eficacia, la precisión y el saber técnico. Aquel irrefrenable proceso acabó con una terrible paradoja: la deshumanización de la humanidad" (Sabato, 2006: 93). El pensamiento de Sabato, uno de los más emblemáticos autores latinoamericanos del siglo XX, sólo puede ser producto de alguien que abandonó la ciencia y el Laboratorio Curie de París para dedicarse a la literatura y el arte, y de un testigo ocular de dos grandes vejámenes de la historia del hombre como lo fueron la Segunda Guerra Mundial y la dictadura en Argentina. De ahí se entiende su propuesta de un mundo más igualitario y solidario, y menos competitivo e individualista, y su crítica respecto a la ponderación excesiva hacia la tecnología en detrimento del espíritu y la humanización del hombre. Ese desvelo en relación con la modernidad la podemos ver en producciones literarias como La Resistencia, entre otras.

Pues bien, muchas de las preocupaciones de Sabato se sitúan en el antagonismo entre el conocimiento occidental y el conocimiento periférico o marginal. Nos invita a pensar en una paradoja, o quizás en una especie de incompatibilidad entre el conocimiento científico, positivado, pasible de medición y experimentación, al servicio de la industria científica o empresarial, y el conocimiento mágico, tradicional o mitológico, base de la resistencia identitaria, la cosmología y la cohesión social de las "minorías" étnicas. De tal forma, en este trabajo nos interesa delinear un plano epistemológico donde estos conocimientos no sean concebidos como polos opuestos entre sí, sino más bien, como estructuras móviles, híbridas y pasibles de interrelacionarse. Esto cobra especial importancia en el marco de la actual crisis del sistema capitalista que ha puesto en jaque la estabilidad ambiental, social y económica del mundo, popularizando las versiones apocalípticas sobre éste.

¿Cuál es el papel de las bibliotecas antes del fin? Sin lugar a dudas, las bibliotecas tienen una gran responsabilidad, principalmente, considerando 
las renovaciones conceptuales posmodernas de la bibliotecología y la ciencia de la información, fruto del advenimiento de las tecnologías de información y comunicación (TIC), las cuales le han permitido dialogar con otras disciplinas esenciales en la actual economía mundial, y le han otorgado a las unidades de información elementos suficientes para construir un campo de acción transversal entre lo social y lo cultural con lo tecnológico e innovador. Sin embargo, es vital reflexionar críticamente sobre el alcance de los paradigmas tecnológicos dominantes que contemplan a la información como agente estratégico e insumo para la toma de decisiones en las compañías, primordialmente desde la óptica de algunos segmentos de la sociedad con características demográficas, sociales y culturales particulares. Esto significa cuestionar las consecuencias de la naturalizada frase "la información es poder", que le concede a los profesionales de la información un papel protagónico en la sociedad del conocimiento, revistiéndolos de una agencia única al ser ellos los llamados a organizar, describir y difundir la información. Para ello, es clave apelar a la dialéctica poder-saber. Foucault apunta que el poder determina qué tipo de saberes privilegia y cuáles excluye, evidenciando la existencia de dos discursos en relación a los saberes, el primero legitimado e institucionalizado (genuinamente aceptado por los que tienen el poder) frente a otro excluido y subordinado, al margen de los criterios definidos por el poder. El filósofo francés recurre al concepto de episteme para denotar el marco o principio ordenador que le confiere legitimidad al conocimiento, permitiéndole proyectarse como una 'verdad' en determinado tiempo histórico:

[...] lo que se intentará sacar a luz es el campo epistemológico, la episteme en la que los conocimientos, considerados fuera de cualquier criterio que se refiera a su valor racional o a sus formas objetivas, hunden su positividad y manifiestan así una historia que no es la de su perfección creciente, sino la de sus condiciones de posibilidad. (Foucault, 1988: 7).

Así pues, este artículo tiene como propósito general esbozar una relación dialógica posible entre la propuesta teórica de la decolonización, las bibliotecas y la propia ciencia de la información, desde una óptica latinoamericanista. Desde ya resaltamos que en términos teóricos estos conceptos pocas veces han sido puestos en diálogo, por lo tanto, más allá de llegar a respuestas conclusivas, en este trabajo buscamos levantar interrogantes que permitan pensar en el papel que las bibliotecas tienen en América Latina, resaltando su compromiso con la recuperación de la cultura, la lengua y las cosmovisiones de los pueblos tradicionales del continente, y la construcción de una política cultural autóctona. De tal modo, esperamos ofrecer algunas herramientas analíticas que motiven a otros investigadores a emprender este camino reflexivo. 


\section{LA DECOLONIZACIÓN DEL CONOCIMIENTO}

Cuando los europeos se encontraron con el "otro" en el siglo XV decidieron tipificarlo según sus lógicas de clasificación, de donde concluyeron que aquellos seres que habitaban el Nuevo Mundo eran inferiores económica, política, cultural y espiritualmente y debían, de manera inexorable, emprender una ruta hacia el progreso y la evangelización. Esta teoría en antropología se conoce como evolucionismo social y su premisa consiste en la existencia de una historia lineal para el desarrollo de las sociedades, las cuales parten de un estado inicial primitivo o de barbarie y gradualmente deben alcanzar un estado ideal de civilización, representado por Europa en ese entonces. Esta concepción etnocéntrica justificaría -y todavía justifica- procesos de esclavitud y etnocidio cuyas consecuencias permanecen latentes hasta nuestros días. Para tener una dimensión histórica de este proceso, por ejemplo, en países como Brasil, la antropóloga Manuela Carneiro da Cunha advierte:

Pueblos indígenas desaparecieron de la faz de la Tierra como consecuencia de lo que hoy se llama, en un eufemismo avergonzado, "el encuentro" de sociedades del antiguo y nuevo mundo. Esa masacre nunca fue vista como un proceso complejo cuyos agentes fueron hombres y microorganismos más cuyos motores últimos podrían ser reducidos a dos: ganancia y ambición, formas culturales de la expansión de lo que se acordó llamar capitalismo mercantil. Motivos mezquinos y no una deliberada política de exterminio consiguieron ese resultado espantoso de reducir una población que estaba cerca de 2 millones en 1500 a los parcos 200 mil indios que hoy habitan Brasil. (Carneiro da Cunha, 1992: 12. Traducción libre)

El pensamiento moderno terminó por instaurar la noción de raza como criterio fundamental para imponer las epistemes occidentales en las colonias. Si nos remitimos a autores como Kant, uno de los pensadores más influyentes de la ilustración y la Europa de los siglos XVIII y XIX, se evidencia una concepción en la cual un hombre libre es un hombre racional, es decir, un hombre que desenvuelve las 'disposiciones originarias' que le confirió la naturaleza para ser 'ciudadano cosmopolita’ y alcanzar la ilustración: "[...] después de muchas revoluciones transformadoras, se realizará lo que la Naturaleza presenta como propósito supremo: un estado de ciudadanía mundial, como el seno en el que se desenvolverán todas las disposiciones del género humano" (Kant, 2004: 17. Traducción libre). Según el filósofo alemán, para que el hombre alcanzara el verdadero conocimiento necesitaba de una serie de intentos de ejercicio y aprendizaje, lo que le garantizaría escalar de forma gradual de un estadio del conocimiento a otro. Así, junto con otros filósofos del 
Siglo de las Luces, se elaboró y defendió una concepción de conocimiento que se reclamaba a sí mismo el derecho de ser universal, validado y demostrado, afirmando al mismo tiempo que los conocimientos no europeos eran especulaciones, dogmas o doxas, parafraseando a Platón. Esta devaluación de ciertos conocimientos en contraposición al elogio de otros también lo podemos ver en el célebre Curso de Filosofía Positiva de Augusto Comte (1984), en el cual cada sociedad necesariamente transita por tres estados del conocimiento para alcanzar su estado evolutivo final, partiendo del estado teológico, pasando por el metafísico hasta llegar al estado positivo. Este raciocinio les confiere a los pueblos 'primitivos' o 'salvajes' una condición de minoría de edad, la cual deben superar para hacer parte de una ciudadanía mundial metropolitana, lo que refleja una postura racista, asimilacionista y homogeneizadora sobre el conocimiento. Es importante advertir que cuando este marco teórico establece los parámetros de quién es sujeto y quién no, proclamando las actitudes y habilidades que deben desenvolverse para ser 'ciudadano', se comete un acto de 'violencia epistémica' (Spivak, 1988).

En este sentido, observamos que la Razón europea se erigió como la expresión máxima del conocimiento, articulando el engranaje del proyecto colonizador en diversas latitudes:

Para Kant, la razón trascendental solamente la tienen aquellos considerados 'hombres'. Si tomamos sus escritos antropológicos, vemos que para Kant la razón trascendental es masculina, blanca y europea [...] los hombres africanos, asiáticos, indígenas, sureuropeos (españoles, italianos y portugueses) y todas las mujeres (incluidas las europeas) no tienen capacidad de razón. (Grosfoguel, 2007: 66).

Incorporar la perspectiva decolonial permite dilucidar analíticamente la relación poder-saber dentro de la lógica del capitalismo global expandido históricamente. El grupo modernidad/colonialidad ${ }^{1}$ sugiere que no nos hemos liberado completamente de las colonias, ya que los procesos de los siglos XIX y XX se redujeron a la independencia jurídico-política de las potencias europeas, por lo cual es fundamental llevar a cabo una decolonialidad que complemente dichos procesos. La decolonialidad se piensa entonces desde una compleja red de relaciones étnicas, raciales, sexuales, epistémicas y de

1 El grupo modernidad/colonialidad es un colectivo multidisciplinar de pensamiento crítico latinoamericano de estudios poscoloniales, que examina desde diversas perspectivas las dimensiones del proyecto de modernidad para la realidad contemporánea de América Latina. Está compuesto por reconocidos intelectuales de la región como el sociólogo peruano Aníbal Quijano, el filósofo mexicano Enrique Dussel, el semiólogo argentino Walter Mignolo, el antropólogo colombiano Arturo Escobar, el filósofo colombiano Santiago Castro-Gómez y el sociólogo puertoriqueño Ramón Grosfoguel, entre otros. 
género, entre otras, que permanecen enraizadas en las sociedades colonizadas y que deben ser desconstruidas para redescubrir nuestra identidad regional política y cultural: “[...] necesitamos buscar 'afuera' de nuestros paradigmas, enfoques, disciplinas y campos de conocimientos. Necesitamos entrar en diálogo con formas no occidentales de conocimiento que ven el mundo como una totalidad en la que todo está relacionado con todo" (Castro-Gómez y Grosfoguel, 2007: 17).

Por lo tanto, esta propuesta teórica plantea que en América Latina es impostergable una crítica a las formas eurocentristas de concepción y producción del conocimiento que se sustentan dentro de la relación centro-periferia y que hoy se proyectan bajo el discurso del desarrollo que promueven los autodenominados centros, el cual se despliega como la única forma de racionalidad posible. Arturo Escobar sugiere que se ha instaurado una institucionalidad que privilegia los patrones occidentales y exógenos que examinan el llamado Tercer Mundo, afirmando que "tal régimen de orden y verdad constituye la quintaesencia de la modernidad, y ha sido profundizado por la economía y el desarrollo. Se refleja en una posición objetivista y empiricista que dictamina que el Tercer Mundo y su gente existen 'allá afuera', para ser conocidos mediante teorías e intervenidos desde el exterior.” (Escobar, 1999: 40)

Para superar dicho estado de dominación cultural y de hegemonía epistemológica es fundamental valorizar la existencia de otros protocolos y modos subalternizados de conocer, transmitir y producir saberes, los cuales se configurarían dentro de una nueva pluralidad epistemológica. De este modo, "decolonizar el conocimiento significa descender del punto cero y hacer evidente el lugar desde el cual se produce ese conocimiento" (Castro-Gómez y Grosfoguel, 2007: 88), para lo cual es menester una revisión crítica de las formas tradicionales de concepción y producción del conocimiento impuestas por Occidente. El filósofo León Olivé cuestiona la exclusividad de los conocimientos científicos y tecnológicos en tanto que son la base de los sistemas imperantes de producción económica; al mismo tiempo, el autor sugiere que para el horizonte de los países latinoamericanos debería hablarse de sociedades de conocimientos y no de una sociedad del conocimiento. En las sociedades de conocimientos debe haber una recuperación de la diversidad cultural, en procura de la mejora de las condiciones de vida de los pueblos tradicionales de la región. Dentro de la visión propuesta por Olivé surgirían los conocimientos o saberes tradicionales como enormes posibilidades para encarar los diferentes problemas sociales y ambientales del planeta:

Un modelo de sociedades de conocimientos adecuado para América Latina debería incluir por lo menos estas tres características: que sean sociedades justas, 
democráticas y plurales. Que una sociedad sea justa significa que contenga los mecanismos necesarios para que todos sus miembros satisfagan al menos sus necesidades básicas y desarrollen sus capacidades y planes de vida de maneras aceptables de acuerdo con su cultura específica. Esto es reconocer el valor de la diversidad cultural, así como la necesidad de respetar y fortalecer cada una de las culturas (ésta es la característica de pluralidad). La tercera característica sería que la toma de decisiones y las acciones se realicen mediante una participación efectiva de representantes legítimos de todos los grupos sociales involucrados y afectados en la formulación de los problemas y en las resoluciones para implementar soluciones (ésta es la democracia participativa). (Olivé, 2009: 20. Cursivas desde el original.)

En esta propuesta de pluralidad epistemológica, la legitimidad de los conocimientos tradicionales no debería basarse en los mismos criterios que se utilizan para juzgar la validez de los conocimientos científicos. En palabras de Boaventura de Sousa Santos, para una emancipación cultural latinoamericana es fundamental "des-pensar para poder pensar" (Santos, 2010: 11-28). Este autor, por su parte, trabaja la noción de una ecología de saberes como una contraepistemología, también basada en un pluralismo, en la cual se entrecruzan diversos 'conocimientos' y diversas 'ignorancias' (la ignorancia la define como una condición descalificadora cuando lo que está siendo aprendido tiene más valor de lo que está siendo olvidado), las cuales no son el estado original o punto de partida de un itinerario que nos transforma en hombres 'cultos', modernos o metropolitanos. No existiría un proceso paulatino de un estado de conocimiento a otro y tampoco una trayectoria determinada para alcanzar un conocimiento 'verdadero', tal y como lo afirmaban los intelectuales de la modernidad.

[...] la ecología de saberes, mientras fuerza la credibilidad para un conocimiento no científico, no implica desacreditar el conocimiento científico. Simplemente implica su uso contrahegemónico. Ese uso consiste, por un lado, en explorar la pluralidad interna de la ciencia, esto es, prácticas científicas alternativas que han sido hechas visibles por epistemologías feministas y poscoloniales y, por otro lado, en promover la interacción e interdependencia entre conocimientos científicos y no científicos. (Santos, 2010:53)

Sin lugar a dudas, esta concepción alterativa sobre el conocimiento se sitúa en una orilla diferente del evolucionismo social, pero no necesariamente la opuesta. Si bien parte de una reflexión crítica sobre la noción de tabula rasa que tienen las sociedades occidentales en relación a las sociedades colonizadas históricamente, donde a estas últimas se les concibe de manera 
ahistórica y subestimada, busca, sobre todo, configurar un terreno epistémico distinto al de la razón en su faceta moderna-europea, con una intención de establecer un diálogo epistemológico entre los saberes. La ecología de saberes implica revitalizar los conocimientos tradicionales, exaltando sabidurías y universos simbólicos condenados al anonimato y a la subordinación, reconociendo que estos conocimientos también tienen importantes aplicaciones en el mundo real, sobre todo si se les ubica en un diálogo bidireccional con las distintas especializaciones y ramificaciones en las cuales el conocimiento occidental se ha dividido, como por ejemplo, en campos como la medicina, la astronomía o la botánica. Así pues, recalcamos que no se trata de emprender una cruzada contra los conocimientos científicos. Lo que queremos destacar, conforme Lévi-Strauss (1989), es que tanto el pensamiento "salvaje" como el pensamiento "científico" están basados en las mismas operaciones lógicas, difiriendo simplemente en sus resultados prácticos; para el francés, los conocimientos indígenas operan sobre la forma de signos (producto de la percepción sensible sobre el mundo), mientras que el conocimiento científico trabaja con conceptos y categorías abstractas. De tal forma, podemos observar que ambas formas de conocimiento no deberían pensarse dentro de una disputa, pues son versiones distintas pero legítimas de la comprensión de mundo:

Existen dos modos diferentes de pensamiento científico, unas y otras funciones, no ciertamente estadios desiguales de desarrollo de espíritu humano, sino dos niveles estratégicos en que la naturaleza se deja abordar por el conocimiento científico uno aproximadamente ajustado al de la percepción y al de la imaginación, y otro dislocado; como si las relaciones necesarias, objeto de toda ciencia, neolítica o moderna, pudiesen ser alcanzadas por dos caminos diferentes: uno muy próximo de la intuición sensible y otro más distanciado. (Lévi-Strauss, 1989: 30. Traducción libre)

Dentro de este panorama, surgen dos preguntas fundamentales: ¿cómo pensar a las bibliotecas desde una ecología de saberes? ¿Qué relación tiene la decolonización del conocimiento con el paradigma de la gestión del conocimiento?

\section{LA ESCRITURA VS LA ORALIDAD}

Para comenzar a responder estos cuestionamientos es conveniente problematizar a la escritura como un medio de comunicación universal y como un sinónimo de cultura. La escritura se constituyó históricamente como el mecanismo por excelencia para el almacenamiento y la transmisión de información; sin 
embargo, como apunta Raúl Fornet-Betancourt, no deberíamos fijar en ella, ni en la elaboración técnica de conceptos, la única forma de comunicación y registro (Fornet-Betancourt, 2004). Naturalmente, las bibliotecas, y en general las unidades de información, obedecen al paradigma de la escritura pues almacenan, custodian, organizan y disponen documentos escritos en diversos soportes, colocándolos a disposición de usuarios -éstos, a su vez, con la capacidad para leer aquello que está escrito- y que posteriormente permiten generar nuevo conocimiento, también escrito, proceso sobre el cual surge la investigación. No obstante, esta cotidiana actividad -por no llamarla obviedad dentro del contexto- es excluyente para los miembros de grupos lingüísticos minoritarios y de comunidades ágrafas, obligadas a aprender las lenguas dominantes (español y portugués -e inclusive inglés- para el caso de América Latina) para sobrevivir y acompañar el ritmo de la globalización. Hoy la escritura, por lo menos la que abunda en los anaqueles físicos y virtuales de las unidades de información, conserva una visión positivista relacionada con una pretensión de 'verdad' sobre la cual se funda la actividad científica. Esto significa que independientemente del área del conocimiento, lo documentos son elaborados sobre paradigmas y principios fruto de la rigurosidad académica y científica, donde el alfabeto se constituye en el dispositivo rector de expresión y representación. En este panorama la oralidad no gozaría de un estatus científico o de una fuente confiable de conocimiento.

José Martí señala que hoy los indios “tercos, sucios o miserables” eran, antes del "encuentro", artistas, gobernantes, guerreros y poetas, y la palabra era una de sus herramientas más fuertes (Martí, 1985). Podríamos citar innumerables fuentes arqueológicas, antropológicas e históricas que dan cuenta de las diversas ciencias que los pueblos ancestrales desenvolvieron y que hoy perfectamente se pueden equiparar con las ciencias más sofisticadas. Partiendo de esta reflexión, no debemos olvidar que en Latinoamérica existen muchas culturas que prefieren la oralidad para transmitir sus saberes, y además, la consideran un instrumento central para organizar la vida al interior de sus comunidades. Como señala Fornet-Betancourt, la imposición de la escritura por parte de algunos pueblos representa la muerte cultural de los sujetos orales, y por ello la oralidad debe entenderse como una forma legítima de organizar el saber, mantenerlo y ofrecerlo a los demás:

En América Latina podemos pensar en el ejemplo de los kunas, cuya mayoría vive hoy día en Panamá. Son una cultura oral, y como tal reivindican su participación en el diálogo intercultural e interreligioso. Pero desde hace ya varios años recogen su memoria también en relatos escritos, aunque el consejo de la cultura kuna hasta ahora siempre fue oral, sigue siendo oral y prefiere la transmisión oral entre ellos. (Fornet-Betancourt, 2004: 35) 
Los bibliotecarios argentinos Edgardo Civallero y Daniel Canosa son dos de los pocos investigadores que trabajan el tema de la oralidad, las bibliotecas indígenas y los servicios bibliotecarios multiculturales en nuestro continente. Dentro de sus trabajos se vislumbran las preocupaciones en torno a la desaparición de lenguas aborígenes de la región y se formula el papel de las bibliotecas en este panorama, las cuales deben asumir un papel activo con la recuperación de la historia oral y la memoria de los pueblos tradicionales:

Por lo tanto hablar de la inserción de "bibliotecas multiculturales" perpetúa en cierto modo la mirada etnocéntrica e incluso racista que se tiene sobre culturas consideradas o asumidas como inferiores según parámetros propios de quienes viven en los llamados "países del primer mundo". Para los bibliotecarios y docentes que trabajan en comunidades indígenas, los conflictos en torno a la lengua son variados y complejos. En muchos pueblos, en especial los que cuentan con variedad de lenguas, adoptar criterios de inclusión de publicaciones en muchas lenguas minoritarias implicaría disminuir la variedad de las colecciones debido a la realización de traducciones bilingües para cada dialecto. En otros casos, la gestación de colecciones plurilingües debería contar previamente con estudios cualitativos y cuantitativos, que permitan definir qué cantidad de dialectos se hablan en la región y que porcentajes de hablantes utilizan esas lenguas. (Canosa, 2008: 5)

De este modo se observa que el paso a la escritura por parte de las comunidades tradicionales es una necesidad para poder alcanzar el paso del proyecto civilizatorio que privilegia un sistema educativo y económico basado en textos y en documentos, no en relatos o narrativas "asistemáticas". Este proyecto, además, relega otro tipo de registros materiales que utilizan los grupos indígenas para crear y compartir conocimiento, como los tejidos y las artesanías; los quipos, por ejemplo, constituyeron uno de los sistemas más utilizados por las civilizaciones andinas para codificar y preservar la información.

A su vez, es primordial reconocer que en América Latina las lenguas normalizadas que hoy conocemos como consecuencia del proceso de secularización y colonización desplazaron a las lenguas naturales, los ritos milenarios y los relatos cosmogónicos de nuestros antepasados, pues se erigieron a sí mismas como una norma. En este orden de ideas, las bibliotecas son instituciones que deben recuperar los llamados 'libros vivientes', es decir, aquellos guardianes de las tradiciones de las comunidades: ancianos, chamanes, pitonisas y artistas (Canosa, 2008), y deben ser centros comunitarios, accesibles y democráticos, donde se promuevan los diálogos horizontales y la traducción intercultural, y donde principalmente se mitigue el preconcepto hacia el diferente, estableciendo los primeros asomos de una ecología de saberes. 
La recuperación de lo ancestral no es tarea fácil, sobre todo considerando que los pueblos indígenas del continente están asociados con los más altos niveles de pobreza, ausencia de derechos, crisis sanitaria, violencia y pérdida de identidad (Civallero, 2008), dado que sus concepciones autónomas de desarrollo y organización social y comunitaria desafían los principios de desarrollo de Occidente. De igual manera, los conocimientos que nortean los rumbos de la sociedad globalizada cargan la herencia de una matriz colonial que consagra los saberes modernos dentro de una racionalidad instrumental económica-capitalista, lo que explica la marginalización de dichas poblaciones desde una óptica del poder-saber. El tema se complejiza aún más si percibimos que el proyecto de la modernidad sigue su paso acelerado. Como afirmó Habermas, el proyecto de la modernidad todavía no se ha completado, es decir, permanece en una trayectoria homogeneizadora y hegemónica más apresurada pues "en todo el mundo occidental se ha producido un clima que refuerza los procesos de modernización capitalista” (Habermas, 1988:34).

\section{LA PARADOJA DE LA GESTIÓN DEL CONOCIMIENTO}

Con una inmensa capacidad premonitoria, en 1988 el austriaco Peter Drucker -considerado el padre de la administración moderna- escribió para la Harvard Business Review lo siguiente: "Now, we are entering a third period of change: the shift from the command and control organization, the organization of departments and divisions, to the information-based organization, the organization of knowledge specialist" (Drucker, 1988: 11), exhortando la importancia que tendría la información y el conocimiento dentro del naciente entorno empresarial. Una década después, los norteamericanos Thomas H. Davenport y Laurence Prusak señalaron que el conocimiento era un recurso estratégico e imprescindible para las corporaciones, el cual determinaría su capacidad productiva (Davenport y Prusak, 1998). Dentro de la sociedad de la información o el conocimiento (concepto de por sí problemático, pues es definido en singular), las nuevas exigencias de la economía requerían que las compañías adoptaran estrategias para capturar, procesar y gestionar dicho conocimiento o know how, con el fin de automatizar sus procesos, aumentar sus ventajas competitivas, y por ende, sus ganancias económicas en el mercado global.

Para efectos del presente análisis, este concepto de conocimiento, si bien se construye sobre la base de las relaciones humanas en función de los ambientes organizacionales, es enclavado dentro de una noción de productividad y competitividad, ciñéndose a la toma de decisiones gerenciales. $\mathrm{La}$ 
gestión del conocimiento se definiría como el "conjunto de acciones que se proyectan y ejecutan -apoyadas en el sistema de información- para formalizar, estructurar e impulsar la aplicación del recurso información para mejorar la productividad y por tanto hacer competitivo un negocio o una empresa en un entorno cada vez más abundante en productos y servicios de información” (Pérez y Coutín, 2005: 6). Fue a finales del siglo XX y a comienzos del siglo XXI cuando el paradigma de la gestión del conocimiento cobró mayor fuerza y renovó las estructuras teórico-prácticas de la administración de empresas, la economía, la ingeniería de sistemas y las mismas ciencias de la información. La incursión de las TIC le ofreció muchas posibilidades y campos de acción a las unidades de información -tanto que hoy son portavoces de conceptos como innovación o emprendimiento- para renovar y optimizar sus servicios y colecciones. No obstante, le planteó igual o mayor cantidad de interrogantes.

En primer lugar, es fundamental percibir que la procedencia de la perspectiva de la gestión del conocimiento nació en los principales epicentros de poder económico y político. A pesar de las desigualdades económicas de América Latina frente a Estados Unidos o Europa, este discurso fue replicado verticalmente. El panorama propuesto por el discurso de la gestión del conocimiento se ubica dentro de otros tantos que procuran la universalización de la cultura y el saber, imponiendo la estandarización de una racionalidad al servicio del capital. Aníbal Quijano sostiene que "ese modo de conocimiento fue, por su carácter y por su origen eurocéntrico, denominado racional; fue impuesto y admitido en el conjunto del mundo capitalista como la única racionalidad válida y como emblema de la modernidad" (Quijano, 2007: 94). La gestión del conocimiento propone que el conocimiento fruto de las experiencias de los clientes y trabajadores de las empresas sea sistematizado, medido, cuantificado y aprovechado. En este sentido, el planteamiento de la información como insumo productivo incurre en una peligrosa visión economicista de la misma, a merced de la economía internacional. Este modelo representa una pretensión por administrar un conocimiento positivado y corporativizado que, además de reproducir en masa las lógicas epistémicas occidentales y de promover el determinismo tecnológico, colateralmente afecta la difusión social del conocimiento, dando lugar a consorcios comerciales que lucran con la investigación científica y los medios para su consulta, los cuales hoy conforman toda una lucrativa empresa internacional del conocimiento. El régimen del copyright y la oportunidad de negocio que ha surgido con la investigación (y todo lo que implican los estudios métricos de la información y el sistema de patentes) obligan a las instituciones, centros de investigación y bibliotecas públicas y privadas a contratar los servicios de 
estas compañías (generalmente provenientes de los tradicionales centros de poder) a costos muy elevados, con el fin de acceder a las publicaciones y herramientas bibliográficas que contienen.

La cibercultura, la producción de subjetividades centradas en el consumo, el paso de una economía fordista, basada en la producción de objetos, a una economía posfordista, centrada en la producción inmaterial (conocimiento e información), el auge de las nuevas tecnologías, son algunas características de este tipo de sociedad, que ha sido identificada con la globalización hegemónica, es decir, con la expansión final y abismal de la lógica del capitalismo en el espacio-tiempo mundial. (Cajigas, 2007: 176)

Vale la pena utilizar un símil que Castro-Gómez hace con la universidad, al apuntar que "el conocimiento que es hegemónico no lo produce ya la universidad bajo la guía del Estado, sino que lo produce el mercado bajo la guía de sí mismo" (Castro-Gómez y Grosfoguel, 2007: 85). Con ello podemos evidenciar que la actividad científica ha adoptado medios más económicos que sociales, tornándose instrumento de los sectores dominantes y renunciando a servir democráticamente a la sociedad, que en esencia debería ser su función. No es casualidad que en los rankings sobre indicadores científicos los cinco países más activos en términos de publicaciones, citaciones y revistas indexadas sean Estados Unidos, Alemania, Inglaterra, Japón y Francia, y dentro del Top 20 sólo aparezca, en el último lugar, un país latinoamericano: Brasil (Science Watch, 2012). Dentro de esta geopolítica del conocimiento -que marca una enorme desigualdad en términos de producción y acceso a la ciencia-, los países históricamente colonizados, hoy "tercermundistas" o "periféricos", van quedando paulatinamente rezagados al avance de la ciencia. El conocimiento de punta sólo está disponible para una minoría que, o bien tiene recursos para pagar por el acceso a estos repositorios, o bien está asociada a alguna universidad o centro de investigación que ha adquirido estas bases de datos bibliográficas y sus servicios.

Sobre esta ruta de análisis, el discurso de la gestión del conocimiento parecería antagónico a la ecología de saberes. No obstante, nos interesa desconstruir estas dicotomías, proponiendo una ruta analítica para pensar en la articulación entre diversas formas de producción del conocimiento, tanto de manera oral como escrita, lo que implica, por un lado, que aquellos conocimientos considerados inferiores, pre-científicos o inmaduros no sean vistos como un obstáculo epistémico para alcanzar 'verdades científicas', y por otro, que las posibilidades tecnológicas/modernas puedan ser apropiadas por los pueblos originarios y posibiliten su autodeterminación y libre expresión. 
Dentro de este nuevo horizonte, la ecología de saberes no implica rechazar el conocimiento científico, ya que "en muchas áreas de la vida social, la ciencia moderna ha demostrado una superioridad incuestionable con relación a otras formas de conocimiento. Hay, sin embargo otras intervenciones en el mundo real que hoy en día son valiosas para nosotros y en las cuales la ciencia moderna no ha sido parte" (Santos, 2010: 53), sino más bien buscar su coexistencia con los saberes tradicionales. En países como Brasil, por ejemplo, la llegada de estudiantes negros e indígenas a las universidades federales ha aumentado durante los últimos años, producto de las políticas de gratuidad de la educación superior, y particularmente, de las políticas de acción afirmativa e igualdad racial que efectivan la igualdad de oportunidades, el combate al racismo y las demás formas de intolerancia étnica en la educación superior; en este proceso también se han creado diversas licenciaturas dedicadas especialmente a los pueblos indígenas. No obstante, la literatura en ciencia de la información todavía no ha abarcado temas como el de las competencias informacionales para estudiantes universitarios indígenas, lo cual marca un desafío para la propuesta que se ha venido desarrollando.

A la idea de la ecología de saberes podría adherirse la de la ecología de información, que nace en el seno de los sistemas de información (si bien existe una corriente sociológica destacada donde se pueden encontrar pensadores como Rafael Capurro), la cual hace referencia a un entorno informacional donde "los sistemas y sus componentes coexisten y se desarrollan gracias a la mutua interacción" (Sebastià I Salat, 2008: 24). Para analizar la interacción de los organismos dentro de un ecosistema hipotético, se deben declarar, definir e identificar las funciones y características de todos los elementos dentro del conjunto; por tanto, en el plano epistémico deseado, deben ser incluidos, sin distinción, todos los tipos y formas de representación del conocimiento, por lo cual la ecología de información está relacionada con una actitud "ética, filosófica, documental, metodológica, sociológica, política" (Sebastià I Salat, 2008: 25) que propicia dicha inclusión e interacción.

Esto nos invita, necesariamente, a descartar idealismos anti-sistémicos y proponer estrategias hacia la práctica intercultural donde las bibliotecas podrían asumir un enorme protagonismo. Para esto podemos encontrar elementos interesantes propuestos por Néstor García-Canclini. Este antropólogo, teniendo en cuenta el carácter dinámico de la cultura, celebra la generación de espacios de hibridación como escenarios de traducción intercultural y de intercambio simbólico que, no obstante, surgen bajo la consciencia de la existencia de un mercado global dominante. Así pues, señala que dentro de la crisis de la modernidad, de la cual América Latina es parte, se transforman 
las relaciones y tensiones entre tradición, tecnología y economía, sobre las cuales las ciencias sociales deben seguir asumiendo un carácter crítico y problematizador:

Así como no funciona la oposición abrupta entre lo tradicional y lo moderno, tampoco lo culto, lo popular y lo masivo están donde nos habituamos a encontrarnos. Es necesario desconstruir esa división en tres pisos, esa concepción hojaldrada del mundo de la cultura y averiguar si su hibridación puede leerse con las herramientas de las disciplinas que los estudian por separado [...]. Necesitamos de ciencias sociales nómadas, capaces de circular por las escaleras que comunican esos pisos. O mejor: que rediseñen los planos y comuniquen horizontalmente los niveles. (García Canclini, 2008: 36)

Tenemos que hablar entonces, paradójicamente, de una renovación de las ciencias de la información dentro de la revolución tecnológica, procurando edificar una bibliotecología autóctona, autocrítica e interdisciplinar. Esto significa que la bibliotecología debe proyectarse como una disciplina social que ha construido su cuerpo epistemológico-práctico sobre postulados antropológicos y sociológicos, en tanto su función es promover todas las manifestaciones de la cultura a sociedades con distintas características. La biblioteca latinoamericana, además, tiene responsabilidades diferenciadas dadas las realidades y especificidades sociopolíticas del continente. Para tal propósito precisamos retirar la reverencia ciega hacia la tecnología y recabar en las necesidades, perspectivas y saberes de campesinos, negros e indígenas otro tipo de usuarios que usualmente no figuran dentro de la literatura académica de los investigadores de las ciencias de la información, y cuyas necesidades deben ser atendidas, pues existen de manera explícita. En reciente entrevista, Alfredo Mires, director de la Red de Bibliotecas Rurales de Cajamarca, Perú, revela el interés que hay en el campo por saber lo que sucede en el mundo, y además advierte la carencia de medios informativos para tal propósito. ${ }^{2}$ En este escenario, este bibliotecario apunta que las bibliotecas juegan un papel preponderante pues son un punto de encuentro, intercambio y acceso informativo; asimismo, son instituciones que surgen como producto de las demandas de los pueblos y se deben sustentar sobre la tradición de estos. De este modo, las bibliotecas latinoamericanas deben concebir las distintas temporalidades y espacialidades que conviven en un mismo presente, pero sobre todo, deben articular lo local y lo global, lo tradicional con lo moderno, comprendiendo que las identidades en la llamada posmodernidad ya no sólidas o estables, sino que se dan en distintos lugares 
y de manera turbulenta y flexible (Marcus, 1991). Esto sobre la perspectiva de promover una verdadera inclusión social, desprendida de una matiz cultural asimilacionista, y volcada hacia el dimensionamiento diferenciado de las culturas, en favor de la lucha por sus derechos:

Si bien las sociedades latinoamericanas se han reconstruido alrededor de las redes digitales de comunicación, los retos sociales a superar siguen siendo los mismos de antaño: la desigualdad, la pobreza, la migración, el desigual desarrollo de los pueblos indígenas, son solo algunos de esos problemas que vienen de tiempo atrás, permanecen y se agravan, independientemente de la modernización constada en algunos ámbitos. (Durán y Ordón, 2011: 88)

Bibliotecas multiculturales: hacia unA POLÍtica CUltural LATINOAMERICANA

Juan Luis Mejía, exministro de cultura de Colombia y con una estrecha relación con el campo de las bibliotecas, resalta que durante los últimos años los estados latinoamericanos se han reconstituido desde la diversidad, lo multiétnico, lo pluricultural y lo intercultural. Mejía cita las constituciones de países como Paraguay, Venezuela, Perú y Colombia, y las más recientes de Bolivia y Ecuador, en las cuales se consagra la identidad cultural como un bastión fundamental para el Estado. No obstante, Mejía subraya que las bibliotecas, archivos, teatros y conservatorios en América Latina siguieron el modelo francés de cultura pregonado por André Malraux, limitándose al fomento de las bellas artes y la protección al patrimonio cultural, donde la cultura sería el fin último del desarrollo (Mejía, 2009). Su crítica apunta a que los países de la región deberían adecuar el sector de la cultura de acuerdo a sus realidades y procesos históricos, lo cual implica abordar la noción de la decolonización epistémica para desmontar el proyecto cultural moderno de Europa que sitúa a las artes y la cultura en el plano de lo sagrado.

Así pues, para el caso latinoamericano es importante descartar a la cultura como sinónimo de erudición. Retomando de nuevo a Martí, debemos comprender que los valores culturales de nuestra región aún siguen en la clandestinidad frente a la ideología de los dominadores, que se autodenominaban 'letrados' o representantes de la cultura 'alta' (Martí, 1985), y, por tanto, es vital la construcción de una política cultural para América Latina que contemple los intereses de las clases históricamente silenciadas, cuya riqueza cultural está invisibilizada. En este sentido, Jesús Martín-Barbero se refiere 
a América Latina como un 'laboratorio de identidades', y por esto defiende una política cultural integral, que asuma sus responsabilidades con lo cotidiano y fortalezca el establecimiento de un tejido comunicativo de lo social. Para este autor la heterogeneidad y la multiculturalidad no deben ser vistas como un problema, sino como la base de la renovación de la democracia (Martín Barbero, 2002: 22).

En este panorama, la biblioteca multicultural, en tanto institución comprometida con la diversidad cultural, surge como una posibilidad de intercambio epistemológico y de confluencia de diversas realidades, tanto occidentales como no occidentales. Como se observa en el manifiesto de la IFLA por la biblioteca multicultural (IFLA y Unesco, 2008), ese trata de una institución clave para el fomento de la coexistencia de diversas visiones de mundo, y debe atender a diversos grupos culturales y lingüísticos que sufren procesos de marginalización en la sociedad. Para esto, la Biblioteca Multicultural debe desarrollar colecciones, servicios y personal adecuado con el fin de atender las necesidades de estas poblaciones.

Naturalmente, las bibliotecas son un sector clave dentro del ámbito de las políticas culturales, y en este sentido, la biblioteca multicultural debe, antes que nada, fundamentarse en un pensamiento crítico, democrático y emancipatorio. No obstante, Canosa apunta que las bibliotecas en América Latina están lejos de alcanzar los parámetros de la IFLA en relación a los servicios multiculturales, dado que estas directrices

fueron concebidas desde la idea de que todos los grupos étnicos, lingüísticos y culturales, ya sean minorías o mayorías, deben disfrutar de un servicio bibliotecario al mismo nivel y de acuerdo a los mismos criterios. Este planteamiento de integración y equidad del servicio bibliotecario no encuentra su correlato en la realidad de América Latina, cuyo patrimonio y riqueza corre riesgo de extinción. (Canosa, 2008: 4)

En este contexto, las bibliotecas multiculturales latinoamericanas deben partir de una formulación diferenciada para ser lugares que favorezcan la ecología de saberes, y sus políticas de acción deben reconocer las particularidades culturales, económicas y políticas del continente. Además, es fundamental que amplíen su espectro del aspecto lingüístico -tal y como lo propone la IFLA-, a una genuina e integral recuperación de los valores culturales ancestrales y populares, que empieza, indudablemente, por una introspección histórica sobre los violentos epistemicidios de los cuales los pueblos indígenas fueron y son objeto. Así mismo, deben ser instituciones comprometidas con la memoria de los pueblos tradicionales, 
y por lo tanto, sus servicios de información deben construirse sobre una plataforma participativa. Canosa sugiere la existencia de "casas de la memoria", que recojan los retazos de la diversidad de nuestra región: historias, valores, costumbres y experiencias espirituales (Canosa, 2008).

Pero, ¿aquellos libros que guardaban los indios de Huehuetan? Y aquellos manuscritos en que los Mayas contaban el poder del písan, el espíritu creador y sentidor, las emociones del puctzikal, el generoso corazón, las magnificencias brahmánicas de su veraz y poderoso Hahalyum, señor de la verdad - y aquellas pinturas de Texcuco, relevadoras, rigurosas de los altos hechos de la dinastía Huitzilopolti. En ninguna parte se hallará que los Obispos en aquellos tiempos desarmaron los leños de la Cruz para hacer con ellos teas con que quemar las memorias vivas y elocuentes de la civilización más original, genuina y autóctona que ha alcanzado pueblo alguno de la tierra. ¡Criminal incienso de aquellas sacrílegas ofertas! - Ídolos, libros, altares, vasos y maravillas del arte hierático, todo vino a los pies del asolador Diego de Landa, y así en Chiapas, y así en Texcuco. Pero de aquella absorción cruenta algo quedó de la vencida raza: el espíritu, que resiste siempre al acero, al hierro y al fuego. (Martí, 1985: 84)

Esta ecología de saberes, como se indicó anteriormente, debe estar en constante diálogo con la tecnología (inspirada en teorías como la ecología de la información), y en general, con las consagradas ciencias modernas. Como muestra Civallero, las TIC están siendo usadas por comunidades indígenas de América Latina para rescatar su patrimonio cultural, difundir la cultura ancestral y dialogar con la sociedad internacional (Civallero, 2008). Otra iniciativa interesante en este sentido han sido los movimientos de activismo digital orientados a rescatar y revitalizar las lenguas indígenas de la región. ${ }^{3}$

Ese diálogo bidireccional no sólo garantizaría un modelo de sociedad que aborde el desarrollo autónomo de los pueblos, sino que permitiría ofrecer condiciones reales para el aprovechamiento social del conocimiento (Olivé, 2009). De este modo, la biblioteca multicultural deberá convertirse en un espacio de encuentro constante donde permeen los relatos orales, los mitos cosmogónicos y las enseñanzas sobre la naturaleza, lo cual, claro está, debe estar en consonancia con los grandes pilares del conocimiento occidental. Además, dentro de la presente formulación de la biblioteca multicultural, debe considerarse la importancia de los sistemas indígenas de conocimiento conocidos como etnociencias: etnomatemática, etnoastronomía, etnobotánica, etnozoología, etnomusicología, etnolingüística, entre otras, para lo cual es fundamental promover su difusión, así como de otros materiales creados 
por las propias comunidades, buscando su integración a los anaqueles y colecciones que albergan las ciencias convencionales.

Esta tarea necesariamente implica la conjugación de esfuerzos del Estado, pero principalmente de la universidad y los sectores gremiales de las ciencias de la información, pues deben reorientar sus esfuerzos logísticos, económicos e intelectuales al servicio de las poblaciones multiculturales, las cuales representan una gran parte de los habitantes del continente y, por ende, un grupo de usuarios con inquietudes, necesidades, fortalezas y carencias informativas:

Aunque muchos factores juegan un papel importante en la prestación de servicio, dos elementos en particular siguen siendo fundamentales para lo bien que la profesión bibliotecaria responderá a una sociedad multicultural en rápido crecimiento. Las divisiones administrativas, tanto la educativa como las organizaciones de todo tipo en Ciencia de la Información, deben renovar el compromiso de mejorar los resultados del servicio para todos los grupos de usuarios con un enfoque en el crecimiento de la población multicultural. (Gollop, 1999: 386. Traducción libre)

La biblioteca multicultural es una aproximación al 'otro'. Reconstruye el sujeto de la colonización y promueve otra consciencia sobre la realidad. Debe ser pensada sobre una teoría crítica decolonial que problematice las implicaciones geopolíticas del conocimiento que trae la idea de centro-periferia, y elimine el racismo epistémico que legitima una jerarquía de dominación sobre los conocimientos no-occidentales. Con miras a este propósito, y con el ánimo de reformular y adecuar las directrices propuestas por organismos supranacionales a los contextos locales, el diseño de servicios de información debe resignificarse y reorientarse a las realidades sociopolíticas propias de las comunidades tradicionales.

En este sentido, en ciertos contextos es clave pensar a la biblioteca multicultural no como un lugar físico, circunscrito a un área geográfica o a una comunidad étnica específica, sino como una gama de servicios interculturales que se pueden integrar a las bibliotecas convencionales (públicas, universitarias, municipales, etc.) donde la biblioteca multicultural sería más bien una categoría analítica que comprende que la cultura en la contemporaneidad es dinámica, fluctuante y móvil, y que puede auxiliar la efectivación de una ecología de saberes. En este sentido, las distinciones moderno-tradicional, epistemes-dogmas o urbano-rural deben ser abolidas, comprendiendo que las poblaciones tradicionales cada vez más están en contacto con la sociedad nacional, y muchos de sus miembros viven en las ciudades.

Este hecho nos invita a pensar en estudios de usuarios mucho más etnográficos que evidencien las formas como las personas aprenden, representan 
y comparten conocimiento en una comunidad dada. En este sentido, surge el desafío de desarrollar servicios de información sobre la base de la coautoría y la construcción a partir de la conversación (Rappaport, 2007), en donde sean abordadas las diversas subjetividades, artes y lenguas en relación al acceso y uso de la información. Dicho diálogo entre profesionales de la información y usuarios de información posibilitaría obtener "nuevas herramientas conceptuales para dar sentido a las realidades contemporáneas” (Rappaport, 2007: 201). Por tanto, es labor de los profesionales de la información estar familiarizados con los censos y levantamientos demográficos de las comunidades donde se encuentran sus bibliotecas, dirigiendo sus esfuerzos a suplir sus necesidades informativas y a fortalecer los procesos de organización y autodeterminación de los grupos marginalizados. Por otro lado, en términos de promoción de lectura y de desarrollo de colecciones, un desafío que existe en la materia es fortalecer las actividades de lectura intercultural y visibilizar el acervo de autores negros e indígenas, con el fin de reducir el desconocimiento y mitigar el racismo que tiene la sociedad nacional sobre los grupos étnicos presentes en los países latinoamericanos.

El planteamiento de la biblioteca multicultural implica al mismo tiempo desconstruir el mito de la neutralidad de la profesión (Jensen, 2008), pues aboga por una militancia de profesionales empoderando a las comunidades a partir de la democratización del conocimiento. Las bibliotecas multiculturales deben recuperar la conexión con la vida y bordar tejidos nuevos con base en lo comunitario, articulando voces interculturales que permitan pensar en infinitas formas de plantearse y responder preguntas sobre la realidad. Quizás de esta manera nos aproximaríamos a la Biblioteca de Babel de Borges, como un mundo híbrido, organizado, pensado y sentido de formas incalculables. Una biblioteca compuesta de un número indefinido de galerías hexagonales, en la que desde cada una se puedan observar los pisos inferiores y superiores del conocimiento (Borges, 2000).

\section{REFLEXIONES FINALES}

Es fundamental reflexionar sobre los desajustes que el proyecto de modernidad trae para América Latina, particularmente desde la óptica cultural y epistemológica. El tema de este trabajo destaca la necesidad de tal teorización y promueve un ejercicio intelectual crítico sobre los cánones disciplinares de las ciencias de la información. El supuesto capitalista del desarrollo concebido como la única forma de racionalidad posible ha sido el bastión para que ciertas sociedades justifiquen el intervencionismo y el sometimiento político, económico y cultural de los pueblos del Tercer Mundo. Aun así, 
es clave reconocer que los países latinoamericanos actualmente son el resultado del entrecruzamiento de tradiciones indígenas, campesinas y afrodescendientes, y al mismo tiempo, del legado colonial católico-europeo y de las políticas tecnológicas y modernistas exógenas. En este sentido, la propuesta de la ecología de saberes busca huir del cliché del sectarismo o la purificación, dado que nace a partir de la consciencia de esta amalgama cultural e invita a pensar en la existencia de sociedades heterogéneas, con tradiciones y racionalidades en permanente tensión, transformación y contradicción, que necesitarían de un ejercicio dialéctico para confluir en contextos de armonización. Para ello se hace necesaria una decolonización del conocimiento, una crítica a las formas eurocéntricas de concepción y producción del conocimiento que se han trasplantado hacia nuestro continente desde tiempos de la colonia, que cuestione los proyectos homogeneizadores sobre la forma como los seres humanos deben pensar, sentir y vivir el mundo, y principalmente, los medios como producen y transmiten la información.

La biblioteca multicultural es una propuesta para el presente latinoamericano, que explora y reedifica el pasado y permite pensar en mecanismos para encarar los retos del futuro. Es una institución que debe, además de atender la inmensa diversidad lingüística de la región, comprometerse ética y políticamente con la situación de sus comunidades. Para que la ecología de saberes sea posible dentro de la biblioteca multicultural, es vital eludir la pretensión de cristalizar el conocimiento que trae consigo la fascinación por colocarlo en una matriz productiva o comercial. Por el contrario, deben generarse servicios de información interculturales que den cuenta de las diversas subjetividades modernas y ancestrales, los cuales también pueden ser apropiados por las bibliotecas tradicionales. Esto coloca al conocimiento dentro de la esfera de lo social, como un fenómeno pulsante y en constante mudanza, por lo que las bibliotecas deben ser lugares donde se difundan las representaciones colectivas y sociales de los pueblos en situación de desigualdad frente a las grandes metrópolis. Así pues, las bibliotecas en América Latina deben ser casas vivas, lugares donde se compartan palabras nuevas y experiencias singulares, escapando, o mejor, auxiliando la representación imperante del conocimiento científico. Son instituciones llamadas a participar en la creación de una política cultural autóctona, que surja sobre la base de nuestros símbolos, historias y necesidades. Son, en definitiva, lugares que deben ayudarnos a pensar en otros mundos posibles, para lo cual, primero debemos estar convencidos que la concepción del mundo es mucho más que la concepción occidental del mundo. 


\section{REFERENCIAS}

Borges, Jorge Luis. 2000. La biblioteca de Babel: prólogos. Buenos Aires: Emecé.

Cajigas, Juan Camilo. 2007. "La biocolonialidad del poder: Amazonía, biodiversidad y ecocapitalismo", en El giro decolonial: reflexiones para una diversidad epistémica más allá del capitalismo global, Santiago Castro-Gómez y Ramón Grosfiguel, (comp.), 169-193. Bogotá: Siglo del Hombre Editores, Universidad Central, Instituto de Estudios Sociales Contemporáneos, Pontificia Universidad Javeriana, Instituto Pensar.

Canosa, Daniel. 2008. "Bibliotecas e inclusión social: coexistir en la diversidad". Educación y Biblioteca 166 (jul.-ago.): 88-94. Fecha de consulta: 11 de enero de 2014. http://gredos.usal.es/jspui/bitstream/10366/119557/1/EB20_N166_P8894.pdf

Carneiro da Cunha, Manuela, org. 1992. Historias dos indios no Brasil, 2da. ed. São Paulo: Companhia das letras, Secretaria Municipal de Cultura, FAPESP.

Castro-Gómez, Santiago y Ramón Grosfoguel, comp. 2007. El giro decolonial: reflexiones para una diversidad epistémica más allá del capitalismo global. Bogotá: Siglo del Hombre Editores, Universidad Central, Instituto de Estudios Sociales Contemporáneos, Pontificia Universidad Javeriana, Instituto Pensar.

Civallero, Edgardo. 2008. "Culturas ancestrales en universos modernos". Digithum 10 (mayo): 1-5. Fecha de consulta: 15 de enero de 2014. http://www.uoc.edu/digithum/10/dt/esp/civallero.pdf

Comte, Augusto. 1984. Curso de filosofía positiva: lecciones 1 y 2. Barcelona: Orbis.

Davenport Thomas y Laurence Prusak. 1998. Working Knowledge: How organizations manage what they know. Boston: Harvard Business School Press.

Durán, Juan y Nilvia Ordón. 2011. "La sociedad del conocimiento y la educación étnica superior: el caso de los estudiantes indígenas de licenciatura", en Educación Superior de carácter étnico en México: Pendientes para la reflexión, Sylvie Didou y Eduardo Remedi (orgs.), 87-101. México: Centro de Investigación en Estudios Avanzados.

Drucker, Peter. 1988. “The coming of the New Organization”. Harvard Business Review (jan-feb): 3-11. Fecha de consulta: 29 de enero de 2015. http://home.base. be/vt6195217/neworganization.pdf

Escobar, Arturo. 1999. El final del salvaje: naturaleza, cultura y política en la antropología contemporánea. Santafé de Bogotá: CEREC, Instituto Colombiano de Antropología.

Fornet-Betancourt, Raúl. 2004. Reflexiones sobre el concepto de Interculturalidad. México: Coordinación General de Educación Intercultural y Bilingüe.

Foucault, Michel. 1988. Las palabras y las cosas: una arqueología de las ciencias bumanas. Buenos Aires: Siglo XXI.

García Canclini, Néstor. 2008. Culturas híbridas: estrategias para entrar y salir de la modernidad. Buenos Aires: Paidós.

Gollop, Claudia J. 1999. "Library and Information Science Education: Preparing Librarians for a Multicultural Society”. College E Research Libraries 60 (4) (jul): 385-395. Fecha de consulta: 01 de marzo de 2015. http://crl.acrl.org/content/60/4/385.full.pdf+html 
Grosfoguel, Ramón. 2007. "Descolonizando los universalismos occidentales: el pluri-versalismo transmoderno decolonial desde aimé césaire hasta los zapatistas", en El giro decolonial: reflexiones para una diversidad epistémica más allá del capitalismo global, Santiago Castro-Gómez y Ramón Grosfoguel (comp.), 63-78. Bogotá: Siglo del Hombre Editores, Universidad Central, Instituto de Estudios Sociales Contemporáneos, Pontificia Universidad Javeriana, Instituto Pensar.

Habermas, Jürgen. 1988. La modernidad un proyecto incompleto. Fecha de consulta: 15 de enero de 2014. http://losdependientes.com.ar/uploads/2ahh8u7z0i.pdf

IFLA (Federación Internacional de Asociaciones de Bibliotecarios e Instituciones) y Unesco (Organización de las Naciones Unidas para la Educación, la Ciencia y la Cultura). 2008. Manifiesto IFLA/UNESCO por la Biblioteca Multicultural. Fecha de consulta: 01 de febrero de 2014. http://www.ifla.org/files/assets/library-services-to-multicultural-populations/publications/multicultural_library_manifesto-es.pdf

Jensen, Robert. 2008. “The Myth of the Neutral Professional”, en Questioning library neutrality: Essays from progressive librarian, Alison Lewis (ed.), 88-96. Duluth: Library Juice Press.

Kant, Immanuel. 2004. Ideia de uma história universal de um ponto de vista cosmopolita, 2da. ed. São Paulo: Martins Fonte.

Lévi-Strauss, Claude. 1989. "A ciência do Concreto", en Pensamento Selvagem, Claude Lévi-Strauss, 15-49. São Paulo: Papirus Editora.

Marcus, George. 1991. "Identidades passadas, presentes e emergentes: requisitos para etnografias sobre a modernidade no final do século XX ao nível mundial”. Revista de Antropologia 34: 197-221. São Paulo: USP.

Martí, José. 1985. El indio de nuestra América. La Habana: Centro de Estudios Martianos.

Martín Barbero, Jesús. 2002. "La globalización en clave cultural: una mirada latinoamericana”. Globalisme et Pluralisme. Colloque international Montreal 22-27 de abril. Fecha de consulta: 13 de abril de 2014. http://www.er.uqam.ca/nobel/gricis/actes/bogues/Barbero.pdf

Mejía, Juan Luis. 2009. "Apuntes sobre las políticas culturales en América Latina, 1987-2009”. Pensamiento Iberoamericano fasc. 4 (2época): 105-130. Fecha de consulta: 20 de marzo de 2015. http://www.pensamientoiberoamericano.org/ xnumeros/4/pdf/pensamientoIberoamericano-97.pdf

Olivé, León. 2009. "Por una auténtica interculturalidad basada en el reconocimiento de la pluralidad epistemológica”, en Pluralismo epistemológico, Luis Tapia (ed.), 19-30. La Paz: Muela del Diablo, Comuna, Consejo Latinoamericano de Ciencias Sociales y CIDES-UMSA.

Quijano, Aníbal. 2007. "Colonialidad del poder y clasificación social”, en El giro decolonial: reflexiones para una diversidad epistémica más allá del capitalismo global, Santiago Castro Gómez y Ramón Grosfoguel (comp.), 93-126. Bogotá: Siglo del Hombre Editores, Universidad Central, Instituto de Estudios Sociales Contemporáneos, Pontificia Universidad Javeriana, Instituto Pensar.

Pérez, Yudith y Adrián Coutín. 2005. "La gestión del conocimiento: un nuevo enfoque en la gestión empresarial”. ACIMED 13 (6) (nov-dic). Fecha de consulta: 30 de enero de 2015. http://scielo.sld.cu/pdf/aci/v13n6/aci040605.pdf

Rappaport, Joanne. 2007. "Más allá de la escritura: la epistemología de la etnografía 
en colaboración". Revista Colombiana de Antropología 43 (ene-dic): 197-229. Fecha de consulta: 01 de noviembre de 2015. http://www.redalyc.org/ pdf/1050/105015277007.pdf

Sabato, Ernesto. 2006. Antes del fin. Buenos Aires: Seix Barral.

Santos, Boaventura de Sousa. 2010. Descolonizar el saber, reinventar el poder. Montevideo: Trilce.

Sebastià I Salat, Montserrat. 2008. "La ecología de la información: un nuevo paradigma de la Infoesfera”. Pliegos de Yuste: revista de cultura y pensamiento europeos 7-8: 23-34. Fecha de consulta: 15 de enero de 2015. http://www.pliegosdeyuste. eu/n78pliegos/pdf/2008-7-8-23-34.pdf

Science Watch. 2012. "Top 20 countries: citations in five-year increments”. Fecha de consulta: 07 de junio de 2015. http://archive.sciencewatch.com/dr/cou/2012/ 12janALLgraphs/

Spivak, Gayatri. 1988. "Can the subaltern speak?", en Marxism and the Interpretation of Culture, Cary Nelson y Lawrence Grossberg (eds.), 271-313. Macmillan Education: Basingstoke.

Para citar este texto:

Gordillo Sánchez, Daniel Guillermo. 2017. "Descolonización, bibliotecas y América Latina: notas para la reflexión”. Investigación Bibliotecológica: archivonomía, bibliotecología e información 73 (31): 131-155.

http://dx.doi.org/10.22201/iibi.24488321.xe.2017.73.57850 